\title{
Nomes deverbais não sufixados e os equívocos da falsa "derivação regressiva" no português brasileiro e europeu
}

\section{Deverbal not suffixed nouns and the misconceptions of the false "backformation" in Brazilian and European Portuguese}

\author{
Graça Rio-Torto* \\ Universidade de Coimbra, Coimbra, Portugal
}

\begin{abstract}
Resumo: A formação de nomes deverbais não sufixados, como afronta, ajuste, despiste, desvio, embarque, engorda, esforço, gargarejo, murmurejo, passeio, voo, tem sido objeto de análises de natureza díspar, no que tange ao seu embasamento teórico e metodológico, à sua história, ao seu modo de construção e/ou à sua morfologia. Neste estudo descrevem-se as questões fundamentais que a descrição destes suscita, os equívocos que ainda subsistem na sua abordagem, e propõem-se soluções metodológicas e teóricas que permitam um tratamento dos nomes deverbais não sufixados consentâneo com o conhecimento mais atualizado dos mesmos. Em 1. apresenta-se o objeto de estudo. Em 2. explora-se a relação cronológica dos nomes com os verbos de base. Em 3. problematiza-se a natureza morfológica da base verbal, bem como a morfologia dos nomes deverbais. Em 4. descrevem-se as áeras temáticas e o semantismo dos nomes deverbais não sufixados. Em 5. traça-se uma panorâmica do percurso deste processo derivacional não sufixal ao longo da história da língua, e avaliam-se as condições de subsistência deste mecanismo concorrencial com outros.
\end{abstract}

Palavras-chave: Formação de palavras. Morfologia. Derivação. Nomes deverbais. Derivados regressivos. Língua portuguesa.

\begin{abstract}
The formation of not suffixed deverbal nouns, such as desvio 'deviation', embarque 'boarding', esforco 'effort', voo 'flight', has received an heterogeneous amount of analyses, namely with regard to their theoretical and methodological ground, their patterns of construction and/or their morphology. This study describes the fundamental issues that the description of these nouns raises, the misconceptions that still exist in their description, and proposes an updated approach to the morphology and wordformation patterns of brazilian and european portuguese not suffixed deverbal nouns. Section 1. presents the aim of the study. Section 2. explores the chronological relationship of the not suffixed deverbal nouns with their verbal bases. Section 3. discusses the morphological nature of the verbal bases and the morphology of the deverbal nouns. Section 4. describes the thematic areas and the semantics of the not suffixed deverbal nouns. Section 5. presents an overview of the not suffixal derivational process throughout the history of the language, and evaluates the conditions of permanence of this mechanism in competition with others.
\end{abstract}

Keywords: Wordformation. Morphology. Derivation. Deverbal nouns. Backformation. Portuguese language.

Departamento de Línguas, Literaturas e Culturas e CELGA-ILTEC, Faculdade de Letras, Universidade de Coimbra, Portugal; gracart@gmail.com 


\section{NOMES DEVERBAIS NÃO SUFIXADOS: INTRODUÇÃO E OBJETIVOS}

A formação de nomes deverbais não sufixados, como afronta, ajuste, despiste, desvio, embarque, engorda, esforco, gargarejo, murmurejo, passeio, voo, tem sido objeto de análises de natureza díspar, no que tange ao seu embasamento teórico e metodológico, à sua história, ao seu modo de construção e/ou à sua morfologia.

Dada a diversidade de estudos publicados no Brasil e em Portugal sobre esta temática, impõe-se uma síntese crítica dos mesmos, em vista a uma clarificação do "estado da arte" e das perspectivas de análise mais atualizadas e cientificamente mais fecundas. Neste estudo descrevem-se as questões fundamentais que a descrição destes nomes suscita, os equívocos que ainda subsistem na sua abordagem, e propõem-se soluções metodológicas e teóricas que permitam um tratamento dos nomes deverbais não sufixados consentâneo com o conhecimento mais atualizado dos mesmos.

Os nomes em análise têm sido encarados como formados por supressão de Vogal Temática e de Morfema de Infinitivo (apoiar > [apoio] N) — visão regressiva tradicional -, como formados por conversão (Rodrigues, 2001, 2009) e nominalização do radical verbal ([apoi $]_{\text {Radical verbal }}>$ [apoi $]_{\text {Radical nominal }}$ ), com necessária adição de vogal temática $\left(\left[[\text { debat }]_{\text {Radical }} \mathrm{e}_{\mathrm{VT}}\right]_{\mathrm{N}},\left(\left[[\text { consum }]_{\text {Radical }} \mathrm{O}_{\mathrm{VT}}\right]\right]_{\mathrm{N}},\left(\left[[\text { permut }]_{\text {Radical }}\right.\right.\right.$ $\left.a_{\mathrm{VT}}\right]_{\mathrm{N}}$ ), ou como sufixação zero [ø] (Resende, 2016). Esta última interpretação parte do princípio de que toda a nominalização deverbal implica sufixação, explícita ou não ([ø]). Não tendo evidências inequívocas de que assim seja, nem tão-pouco de que este mecanismo esteja assente num processo de conversão de radicais (Rodrigues, 2004), opta-se aqui por "formação de deverbais não sufixados", tal como Rodrigues (2016, p. 235).

Em 2. explora-se a relação cronológica dos nomes com os verbos de base. Em 3. problematiza-se a natureza morfológica da base verbal, bem como a morfologia dos nomes deverbais. Em 4. descrevem-se as áreas temáticas e o semantismo dos nomes deverbais não sufixados. Em 5. traça-se uma panorâmica do percurso deste processo derivacional não sufixal ao longo da história da língua, e avaliam-se as condições de subsistência deste mecanismo concorrencial com outros.

\section{NOMES DEVERBAIS NÃO SUFIXADOS E SUA RELAÇÃO CRONOLÓGICA COM OS VERBOS DE BASE}

Um nome deverbal, e ainda mais se encarado como derivado "regressivo", ou seja, como formado por retroformação supressiva, supõe a existência prévia de uma base verbal. Nesta secção procuraremos observar a cronologia relativa dos verbos e dos nomes corradicais, para verificar se os nomes deverbais estão abonados, ou não, antes do respetivo verbo de base. Importa desde já afirmar que a cronologia relativa das ocorrências de ambos não funciona como critério único e decisivo para a correlação estrutural entre uns e outros. Como assinala Rodrigues (2001), as dimensões de natureza morfossemântica que a estrutura e interpretação dos nomes convoca, ajudam a, complementarmente, determinar a natureza deverbal destes nomes. Em todo o caso, sob o ponto de vista genético, um derivado postverbal supõe a existência prévia — real e/ou teórica — do verbo de base. 
Dos 1323 nomes deverbais não sufixados elencados em Rodrigues (2001), selecionamos aleatoriamente os que constam do quadro abaixo, com estrutura morfológica diversa e graus diversos de frequência no PE. Em alguns casos os nomes em estudo são cognatos de outros igualmente deverbais, mas sufixados (em ção, -mento, -agem, -ncia) e portadores do mesmo radical.

As datas dos $\mathrm{N}$ e dos $\mathrm{V}$ são extraídas do dicionário etimológico de $\mathrm{A}$. G. da Cunha; quando mencionado de forma ad hoc, as datações foram recolhidas em bases de dados, como o www.corpusdoportugues.org. No quadro 1, sublinhados figuram os casos em que $\mathrm{V}$ é posterior a $\mathrm{N}$. A negrito os casos dos $\mathrm{N}$ cujas primeiras abonações de que dispomos são contemporâneas das dos V. Quando a ortografia diverge da atual, seja a do $\mathrm{N}$, seja a do $\mathrm{V}$, ambas são explicitadas.

Quadro 1 - Cronologia das abonações de Nomes (N) e de Verbos (N)

\begin{tabular}{|c|c|c|c|c|c|c|c|c|}
\hline & $N$ & V & & $N$ & V & & $N$ & V \\
\hline $\begin{array}{c}\text { abandono } \\
\text { (do fr. abandon) }\end{array}$ & 1813 & XVI & rateio & 1813 & XVI & desempenho & 1813 & 1813 \\
\hline ajuda & XIII & XIII & relance & 1813 & XVIII & abafo & XVI & $\mathrm{XV}$ \\
\hline amostra & 1500 & XIII & desempate & XVIII & $1750 ?$ & uivo & 1813 & $\begin{array}{c}\text { XIV } \\
\text { (huyar) }\end{array}$ \\
\hline apoio & XVII & $\mathrm{XV}$ & $\begin{array}{l}\text { arrepio } \\
\text { (arripio) }\end{array}$ & XVI & XV & transbordo & 1899 & 1844 \\
\hline ataque & XIX & XIX & escape & XVIII & XIII & salga & $\mathrm{XV}$ & XIII \\
\hline atraso & 1813 & XVI & zanga & 1844 & 1813 & arroto & $\underline{\mathrm{XIV}}$ & $\underline{\mathrm{XVI}}$ \\
\hline combate & XIV & XIII & troça & 1881 & 1881 & mexerico & XVI & XVI \\
\hline confronto & 1881 & XVI & pertença & XIII & XIII & paga & XIII & XIII \\
\hline consumo & 1813 & XIII & embarque & 1802 & $\mathrm{XV}$ & desgoverno & XVII & $\mathrm{XV}$ \\
\hline corte & XVI & XIII & ajuste & 1813 & 1658 & estalo (estralo) & XVI & XIII \\
\hline $\begin{array}{c}\text { debate } \\
\text { (do fr. débat) }\end{array}$ & XV & $\mathrm{XV}$ & desembarque & 1813 & XVII & $\underline{\text { varejo }}$ & $\underline{X V ?}$ & $\begin{array}{l}\underline{X V I} \\
\underline{1504-} \\
\underline{1548} \\
\end{array}$ \\
\hline desempenho & 1813 & 1813 & recuo & XVIII & XVI & trago & XVI & XVI \\
\hline desemprego & 1899 & 1858 & saque & XVI & XVI & $\underline{\text { urro }}$ & $\underline{\mathrm{XV}}$ & $\underline{\mathrm{XVI}}$ \\
\hline destaque & 1899 & XIII & anseio & XIX & XIV & $\begin{array}{c}\text { apanha } \\
\text { (do cast. apañar) }\end{array}$ & XIX & XIII \\
\hline desvio & XVI & XIII & abalo & 1562 & XIII & enfado & XVII & XIII \\
\hline emprego & $\mathrm{XV}$ & $\mathbf{X V}$ & festejo & XVIII & 1572 & palpite & 1881 & XVI \\
\hline
\end{tabular}




\begin{tabular}{|c|c|c|c|c|c|c|c|c|}
\hline \multirow[b]{2}{*}{ ensino } & & $V$ & \multirow[b]{2}{*}{ retoque } & & $V$ & \multirow[b]{2}{*}{ chilreio } & $N$ & $V$ \\
\hline & XIV & XIII & & XVII & XVII & & 1844 & $1697^{1}$ \\
\hline espera & 1813 & XIII & queima & XV & XIII & $\begin{array}{c}\text { visita } \\
\text { (do fr. visite) }\end{array}$ & XVII & XIV \\
\hline roubo & XIII & XIII & permuta & XVII & $\mathrm{XV}$ & voO & XIX & $\begin{array}{r}\text { XVI } \\
\text { (avoar) }\end{array}$ \\
\hline toque & XVI & XV & & & & & & \\
\hline
\end{tabular}

No quadro acima, em três casos os nomes podem representar importações do francês $(\operatorname{abandono}(\mathrm{N})$ do fr. abandon, debate $(\mathrm{N})$ do fr. débat, visita $(\mathrm{N})$ do fr. visite) e num caso $(a p a n h a(\mathrm{~N}))$ pode ter havido influência do cast. apañarem, apanha.

Do universo de nomes e de verbos analisados, apenas em três casos a datação disponível do verbo é posterior à dos nomes. Trata-se de nomes com valores de frequência de uso muito baixos (arroto \#15, varejo \#6 e urro \#27), e o desfasamento epocal entre a abonação disponível do $\mathrm{N}$ e do $\mathrm{V}$ não ultrapassa um século (cf. urro(N) (séc. XV) e urrar (séc. XVI)). No caso de $\operatorname{arroto}(\mathrm{N})$ (séc. XIV) e arrotar (séc. XVI) é provável que uma análise minuciosa de outras fontes altere o estado de coisas aqui descrito, pois também se encontra documentado rotamento, por arrotamento (séc. $\mathrm{XV}$ ), sendo possível que haja grafias alternativas de arrotar não tidas em conta nas fontes compulsadas. Quanto a varejo $(\mathrm{N})$, Cunha assinala a sua ocorrência no séc. XV, não especificando onde, e encontra-se documentado em 1589 (www.corpusdoportugues.org), pelo que pode ser anterior ou posterior a varejar (1504-1548).

Em dez casos (cerca de $1 / 6$ do total) as primeiras abonações até agora disponíveis de $\mathrm{N}$ e de $\mathrm{V}$ coincidem no mesmo século: ajuda $(\mathrm{N})$ e ajudar (séc. $\mathrm{XIII}$ ), ataque $(\mathrm{N})$ e atacar (séc. XIX), desempate $(\mathrm{N})$ e desempatar (séc. XVIII), desempenho(N) e desempenhar (1813), emprego(N) e empregar (séc. XV), paga(N) e pagar (XIII), roubo(N) e roubar (séc. $\mathrm{XIII})$, saque $(\mathrm{N})$ e sacar $(\mathrm{XVI})$, retoque $(\mathrm{N})$ e retocar $(\mathrm{XVII})$, troça $(\mathrm{N})$ e troçar (1881).

Face ao exposto, a cronologia relativa dos nomes e dos verbos é maioritariamente favorável à posterioridade dos nomes relativamente aos verbos, o que serve de garante, pelo menos complementar, à natureza deverbal dos nomes.

A cronologia, a história e a etimologia das palavras podem ser de enorme ajuda para o esclarecimento da direcionalidade da formação nome $>$ verbo ou verbo $>$ nome, mormente quando não há parâmetros formais ou semânticos que permitam clarificar qual a base da unidade lexical.

Por exemplo, em pares do tipo de gritar/grito, trabalhar/trabalho, a estrutura fonológica e morfológica não deixa perceber se o nome é derivado ou derivante. A consulta de Cunha permite observar que gritar, documentado desde o séc. XVI, tem

1 Em Cunha o V chilrear encontra-se datado de 1844, mas no www.corpusdoportugues.org testemunha-se chilrear na Prosodia 4, de Bento Pereira, obra de 1697. 
origem no latim *CRITĀRE, de QUIRITĀRE. Já grito está abonado no séc. XIV e grita, desde 1572. Quanto a trabalho (< TRĬPĀL $\breve{I U}$ ) e trabalhar (do lat. vulgar *TRĬPĀLIĀRE) ambos documentados desde o séc. XIII, o semantismo de trabalbo 'labor, ocupação' já não se relaciona com o do seu étimo 'instrumento de tortura composto de três paus'. Ou seja, face à dificuldade em determinar, mormente em cotextos menos clarificadores (dar um grito, fazer uma busca), o estatuto derivante ou derivado do nome, as informações históricas e/ou etimológicas são de grande mais valia para a solução do problema.

Não obstante, a cronologia e a etimologia não se afiguram por si sós, critérios decisivos e únicos para a determinação da forma de construção dos nomes em estudo. Como afirma Rodrigues (2001, p. 106),

\begin{abstract}
o critério diacrónico não deve ser tomado como o principal fundamentador da delimitação dos postverbais. Para que essa delimitação se possa operar, é necessário compreender as características morfofonológicas, semânticas e sintáctico-semânticas dos postverbais. Uma abordagem diacrónica pode fornecer indícios acerca das coordenadas temporais e espaciais — o espaço que é a língua — que envolvem a génese dos lexemas. Todavia, ela não apresenta uma construção sistémica dos traços do lexema. Em suma, a abordagem discrónica não é em si mesma definitória do post verbal.
\end{abstract}

\title{
3 MORFOLOGIA DOS VERBOS DE BASE E DOS NOMES FORMADOS POR NÃO SUFIXAÇÃO (E NÃO POR SUPRESSÃO/RETROFORMAÇÃO)
}

Como já foi amplamente demonstrado (cf. Rodrigues, 2001, 2016, \$1.6.3.2 Nomes deverbais conversos), estes nomes não são regressivos, no sentido em que seriam formados por supressão de constituintes, nem portanto por retroformação. Não obstante terem uma forma mais encurtada que a de infinitivo verbal — veja-se, por exemplo avisar e aviso, bocejar e bocejo, ensinar e ensino —, o nome não provém de nenhuma forma flexiva, pois para tal esta, que é imposta e formatada sintaticamente, teria sido truncada/privada de um dos seus morfemas flexionais para dar origem a um produto derivacional. Ora, a formação de unidades lexicais não toma por base formas flexionadas, pois a ativação destas é comandada por motivações sintáticas, ao serviço das quais está: a flexão do verbo, em modo, tempo, número-pessoa; é gerida em função de razões sintático-semântico-textuais, e não de razões derivacionais:

(1) (nós) $\left[[\text { dize }]_{\text {tema verbal }}[\text { mos }]_{\left.\left.\text {Morfema de } 1^{\circ} \text { pessoal do plural }\right]\right]}\right.$

(2) (tu) [[tarda $\left.\left.]_{\text {tema verbal }}[\mathrm{va}]_{\text {morfema de imperfeito do indicativo }}[s]_{\text {Morfema de } 2^{\circ} \text { pessoa do singular }}\right]\right]$

(3) (vocês) $\left[[\text { fare }]_{\text {tema verbal }}[m]\right.$ Morfema de $3^{\circ}$ pessoa do plural $\left.]\right]$

As bases de uma unidade lexical são temas ou radicais lexicais (cf. Basílio, 2004; Rio-Torto et al. 2016), prototipicamente ainda não marcados flexionalmente.

$\mathrm{Na}$ base dos derivados deverbais não está uma forma flexiva, mas um tema (lavá $+v e l$, gere $+n t e$, contribui + nte, repetítvel) ou um radical (aldrab+ão, deambul $+i s m o)$, logo formas verbais ainda não providas das vogais de flexão. 
Os nomes em estudo também não são deverbais formados por redução ou por truncação, como boteco, de botequim, belê, de belez̧a, madruga, de madrugada, salafra, de salafrário.

Todavia, em muitas gramáticas e estudos de referência (Azeredo, 2013; Basílio, 2004; Bechara, 2004; Gamarski, 1988; Gonçalves, 2016) este processo de formação de nomes deverbais continua a ser descrito como derivação ou formação "regressiva". De modo similar, a denominação de backformation é a mais usada para a língua inglesa.

Não são unânimes as posições sobre a classe morfológica da base destes nomes, que têm origem num radical do verbo, seja o radical o de infinitivo (Rodrigues, 2001) ou o de presente do indicativo (Diez, 1838; Kehdi, 1998) como francês maintien, soutien, relief, e o espanhol pide.

Há evidências de que estes nomes deverbais replicam o radical das formas rizotónicas do presente do indicativo; confirmam-no exemplos do espanhol consuelo (de consolar), sueño (de soñar), do francês soutien (de soutenir), preuve (em fr. antigo prueve, "issu des anciennes formes toniques du verbe [prowver] avec accent sur le radical" (Rey, 2011), com a conhecida alternância vocálica entre formas rizotónicas e arrizotónicas), e as portuguesas bloqueio (de bloquear), cambaleio (de cambalear), galanteio (de galantear), manuseio (de manusear), pastoreio (de pastorear), rateio (de ratear), rastreio (de rastrear), receio (de recear), veraneio (de veranear). Em todo o caso, a forma de base é o radical verbal, e não a forma flexionada de $1{ }^{\mathrm{a}} / 3$. $^{\mathrm{a}}$ pessoa do singular do verbo. Com estas evidências cai por terra a pertinência de um modelo de análise morfológica baseado na palavra, que muitas vezes se socorreu deste tipo de derivados (putativamente derivados do infinitivo verbal) para se legitimar. Neste aspeto, não existe dissidência entre o paradigma lexicalista e o distribuidista da morfologia, tão exaustivamente glosada nos anos mais recentes.

Os deverbais que exibem alternância acentual são cultos, logo mais tardios na língua portuguesa, o que, segundo Kehdi (1998, p. 205-206)

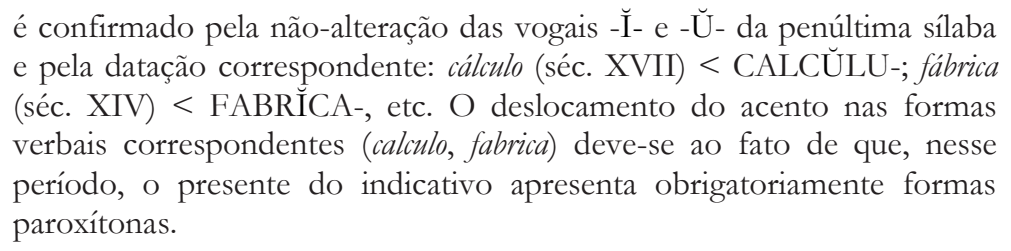
e pela datação correspondente: cálculo (séc. XVII) < CALCŬLU-; fábrica (séc. XIV) < FABRICA-, etc. O deslocamento do acento nas formas verbais correspondentes (calculo, fabrica) deve-se ao fato de que, nesse período, o presente do indicativo apresenta obrigatoriamente formas paroxítonas.

Sob o ponto de vista morfológico, as bases verbais destes nomes podem ter estruturas morfológicas diversas (Rodrigues, 2016):

(i) bases simples não derivadas: jantar $>$ janta, sacar $>$ saque

(ii) bases simples derivadas (verbos conversos): balançar $>$ balanço

(iii) bases derivadas por prefixação: afrontar $>$ afronta, despistar $>$ despiste, embarcar $>$ embarque, engordar $>$ engorda; esforçar $>$ esforço

(iv) bases derivadas por sufixação: chorincar>chorinca, passear>passeio, pedinchar $>$ pedincha, pestanejar>pestanejo

(v) bases derivadas por circunfixação: aboquejar $>$ aboquejo, acarrear $>$ acarreio, espinotear>espinoteio

(vi) bases complexas não derivadas: conversar $>$ conversa, pernoitar>pernoita. 
Estes nomes deverbais não tomam por base verbos em -ec- ou -esc(*amadureço, *amareleço, *envelheço, * ruboresço). Apenas se documenta um deverbal não sufixado formado com base num verbo em -i $\tilde{-}_{-}$(vocalizo), mas este tipo de bases encontra-se tipicamente indisponível para a formação de nomes deverbais não sufixados. Também o mesmo acontece com bases verbais em -ific-. Este mecanismo de formação de nomes opta claramente por estruturas não eruditas, mas alguns nomes (permuta, perlonga, deslustre) acusam marcas claras da sua origem greco-latina.

Em francês estes nomes são essencialmente da primeira conjugação. Em português, estão abonados muitos nomes da primeira conjugação, o que não espanta sendo esta a mais produtiva, mas também da segunda (cf. debate, pertença) e da terceira (cf. o consumo, de consumir, a funda, de fundir) conjugações.

Não discutiremos aqui o problema da direcionalidade relativa dos $\mathrm{N}$ face aos $\mathrm{V}$, pois trata-se de temática amplamente dirimida e ultrapassada através da conjugação de critérios semânticos, morfológicos, fónicos e etimológicos.

Em todo o caso, e porque em pares do tipo de avisar/aviso a estrutura fonológica e morfológica não deixa perceber se o nome é derivado ou derivante, explicitam-se os critérios que permitem essa identificação (cf. Rodrigues, 2001; Rodrigues, 2009):

(i) o verbo é derivante e o nome é derivado se estiverem presentes os prefixos $a-, e n-, d e-, e s-$, uma vez que estes apenas atuam na formação de verbos (atacar $>$ ataque, demorar $>$ demora, encaixar $>$ encaixe, esforçar $>$ esforco) e des-, que atua prototipicamente na formação de verbos e de adjetivos, não tanto na de nomes (desempenhar $>$ desemepenho).

(ii) é derivante o nome com acentuação proparoxítona (análise $>$ analisar, crítica $>$ criticar, dúvida $>$ duvidar, âncora $>$ ancorar $)$.

(iii) é derivante o verbo de tema em - $e$ ou em $-i$, porque a formação de novos verbos do português recorre à VT $-a$.

(iv) é derivado o nome que exibe estrutura argumental (a recolha do lixo pelos trabalhadores vs. *o muro de pedra pelo João).

(v) é derivante o nome portador de semantismos de caráter apenas concreto (e nunca eventivo): muro 'estrutura que separa terrenos ou forma uma cerca' $>$ murar 'prover de muro'). É derivado o nome que apresenta significação abstrata de evento: atavio 'conjunto de operações que constituem o cuidado no vestir', a par com 'enfeite, adorno'.

\section{4 ÁREAS TEMÁTICAS E SEMANTISMO DOS NOMES}

Durante muito tempo afirmou-se que estes nomes recobrem áreas temáticas ligadas ao mundo rural, artesanal, não tecnologizado, como o da agricultura, pecuária, pesca mais tradicionais, e assim é de facto com muitos nomes (Rodrigues, 2004, p. 129-185). Nestas circunstâncias, é natural que alguns sejam apenas conhecidos e/ou usados em Portugal, outros apenas no Brasil, havendo muitos que são comuns a ambos os universos, mas que, de tão pouco usados, o mais das vezes um falante comum, e até mesmo diferenciado em termos de instrução formal, desconhece e/ou não usa. Todavia, como veremos mais abaixo, este estado de coisas só parcialmente é verdadeiro, pois há muitos nomes deverbais não sufixados de elevado valor de frequência e de sentido não circunscrito aos domínios acima mencionados, que são 
comuns ao Português Brasileiro (PB) e ao Português Europeu (PE), bem como às variantes africanas da Língua Portuguesa.

Comecemos por atentar nos produtos menos comuns, porque mais específicos de cada universo linguístico-civilizacional do PB e do PE.

No dicionário Houaiss e no Aurélio não figuram alguns nomes que os dicionários do PE registam, tais como:

(4) debagar> debaga 'ato ou efeito de debagar, de tirar os bagos a'

(5) desabelhar 'debandar como enxame de abelhas' > desabelho 'ação ou efeito de desabelhar; desabelhamento; fuga em bando; desarvoramento; recolha de mais de um enxame no mesmo cortiço'

(6) descamisar 'tirar a camisa; tirar as folhas que envolvem a maçaroca do milho' > descamisa 'ação de tirar as folhas que envolvem a maçaroca do milho'

(7) alimpas 'resíduos dos cereais depois de serem joeirados'

Deve dizer-se que no mundo atual, preocupado com a sustentabilidade e com as boas práticas de natureza ambiental e alimentar, estas atividades outrora depreciadas, porque artesanais, são agora alvo de enorme valorização até económica. Em Portugal, a fileira agro-alimentar de nicho dos setores vitivinícola e silvícola, por exemplo, recorre à produção de produtos de valor acrescentado com recurso a técnicas manuais, de transformação artesanal, biológica, porque mais ecológica e de elevado valor acrescentado, pelo que a debaga ou a debulha, além de não caírem em desuso, deixam de ser objeto de depreciação para passar a integrar áreas de crescente valorização a todos os níveis.

No Brasil há também nomes deverbais não sufixados não usados em Portugal, ou usados no PE com outros valores e/ou em outros contextos (cf. (12 e 13)):

(8) (o) afrouxo 'desaceleração; suavização; redução', de afrouxar

(9) (o) arraso 'Algo ou alguém que faz muito sucesso ou tem muita popularidade: a festa foi um arraso! Ação ou efeito de arrasar, de destruir: a chuva foi um arraso para a plantação' (Houaiss), de arrasar

(10) (o) aprovo 'ato de aprovar, dar aprovação, aval', de aprovar

(11) (a) desossa 'processo de desossar; desossamento', de desossar

(12) (o) desquite 'ato de desquitar (-se); separação judicial de um casal; divórcio; separação' [no PE usa-se mais separação, divórcio]

(13) (o) preparo 'preparação; disposição preliminar': no PB regista-se amiúde preparo de alimentos, e no PE, para a mesma circunstância, a formulação tipicamente usada é preparação de alimentos.

São comuns ao PB e ao PE muitos nomes, como os abaixo mencionados; porque não usados na língua comum, são por certo desconhecidos até de falantes com elevado grau de instrução formal:

(14) debulbo 'Resíduo das espigas dos cereais depois de debulhados, constituído de casulos e praganas' (Houaiss e Dicionário Priberam)

(15) ensancha 'Porção que se deixa a mais, embebida na costura, para se poder alargar a roupa quando for preciso' (Houaiss e Dicionário Priberam)

(16) inço 'Vegetais que durante a colheita são poupados para frutificarem. Restos, resquícios: por mais que se destruam os insetos daninhos, sempre fica inço. 
Ervas daninhas que crescem entre plantas cultivadas' (Houaiss e Dicionário Priberam)

Todavia, um olhar criterioso sobre as áreas temáticas dos nomes em pauta, revela que no conjunto das unidades mais frequentes, incluem-se muitas que são comuns ao $\mathrm{PE}$ e ao $\mathrm{PB}$ (e às demais variantes pluricêntricas da Língua Portuguesa), e que espelham as zonas de preocupação maior do mundo contemporâneo (emprego e desemprego, ensino, atraso, consumo, apoio, ajuda, abandono, ataque, combate, confronto, roubo, voo), refletindo portanto a importância cultural e vivencial do que denotam; os exemplos seguintes, em que a cada nome está associada a frequência CORLEX respetiva, ilustram o exposto:

(17) apoio \#3636, visita \#2269, emprego \#2200, espera \#2184, ensino \#1851, debate \#1631, consumo \#1575, ataque \#1512, ajuda\#1233, combate \#994, desemprego \#942, atraso \#864, voo \#838, roubo \#380, abandono \#437, confronto \#353.

No quadro seguinte \# indica o valor de frequência CORLEX ${ }^{22}$, que se explicita para melhor se visualizarem os patamares de frequência de uso dos nomes nele presentes. Note-se que 10 nomes têm frequência superior a 1000, 22 têm frequência superior a 350, e apenas 18 apresentam frequência igual ou inferior a 51. Para se ter uma noção do peso relativo, em termos de uso, de cada um dos itens, note-se que na base de dados CORLEX os valores de frequência (\#) da preposição $a$ e de são, respetivamente, \#23858 e \#741070.

Quadro 2 - Valores de frequência dos lemas (N) extraídos de CORLEX

\begin{tabular}{|c|c|c|}
\hline Frequência $>350$ & Frequência $52<200$ & Frequência $\leq 51$ \\
\hline (1) destaque $(\mathrm{N})$ \#9531 & (1) recuo $(\mathrm{N}) \# 169$ & (1) estalo (N) \#51 \\
\hline (2) apoio $(\mathrm{N}) \# 3636$ & (2) arrepio (N) \#139 & (2) uivo $(\mathrm{N}) \# 51$ \\
\hline (3) visita (N) \#2269 & (3) queima $(\mathrm{N}) \# 130$ & (3) palpite $(\mathrm{N}) \# 37$ \\
\hline (4) emprego (N) \#2200 & (4) anseio $(\mathrm{N}) \# 122$ & (4) trago $(\mathrm{N}) \# 37$ \\
\hline (5) espera $(\mathrm{N}) \# 2184$ & (5) festejo (N) \#109 & (5) apanha $(\mathrm{N}) \# 36$ \\
\hline (6) ensino (N) \#1851 & (6) abalo (N) \#96 & (6) urro (N) \#27 \\
\hline (7) debate $(\mathrm{N}) \# 1631$ & (7) ajuste $(\mathrm{N}) \# 95$ & (7) paga $(\mathrm{N}) \# 24$ \\
\hline (8) consumo $(\mathrm{N}) \# 1575$ & (8) pertença $(\mathrm{N}) \# 95$ & (8) mexerico $(\mathrm{N}) \# 23$ \\
\hline (9) ataque $(\mathrm{N}) \# 1512$ & (9) esca Port. Eur. (N) \#94 & (9) transbordo $(\mathrm{N}) \# 21$ \\
\hline (10) ajuda $(\mathrm{N}) \# 1233$ & $(10)$ relance $(\mathrm{N}) \# 88$ & (10) abafo $(\mathrm{N}) \# 16$ \\
\hline (11) combate $(\mathrm{N}) \# 994$ & (11) troça $(\mathrm{N}) \# 87$ & (11) uivo $(\mathrm{N}) \# 15$ \\
\hline (12) desemprego (N) \#942 & (12) desembarque $(\mathrm{N}) \# 79$ & $(12) \operatorname{arroto}(\mathrm{N}) \# 15$ \\
\hline$(13)$ atraso $(\mathrm{N}) \# 864$ & (13) zanga $(\mathrm{N}) \# 77$ & (13) desgoverno $(\mathrm{N}) \# 10$ \\
\hline$(14) \operatorname{voo}(\mathrm{N}) \# 838$ & (14) permuta $(\mathrm{N})$ \#76 & (14) salga $(\mathrm{N}) \# 9$ \\
\hline
\end{tabular}

2 O CORLEX (cf. www.clul.ul.pt/pt/recursos/88-project-multifunctional-computational-lexicon-ofcontemporary-portuguese) é um corpus de frequência lexical organizado pelo Centro de Linguística da Universidade de Lisboa com base em 16.210.438 palavras do Corpus de Referência do Português Contemporâneo, e a ele se recorreu para apurar a frequência absoluta dos lemas nominais em estudo. A adjunção de $(\mathrm{N})$ a cada item lexical destina-se a explicitar que se trata dos lemas nominais, e não das formas verbais homólogas também no mesmo corpus incluídas. 


\begin{tabular}{l|l|l}
\multicolumn{1}{c|}{ Frequência $>350$} & \multicolumn{1}{|c}{ Frequência $52<200$} & \multicolumn{1}{|c}{ Frequência $\leq 51$} \\
\hline (15) desvio $(\mathrm{N}) \# 505$ & (15) retoque $(\mathrm{N}) \# 66$ & (15) chilreio $(\mathrm{N}) \# 9$ \\
(16) corte $(\mathrm{N}) \# 500$ & (16) rateio $(\mathrm{N}) \# 65$ & (16) enfado $(\mathrm{N}) \# 7$ \\
(17) toque $(\mathrm{N}) \# 457$ & (17) saque $(\mathrm{N}) \# 65$ & (17) desempeno $(\mathrm{N}) \# 6$ \\
(18) abandono $(\mathrm{N}) \# 437$ & (18) embarque $(\mathrm{N}) \# 58$ & (18) varejo $(\mathrm{N}) \# 6$ \\
(19) amostra $(\mathrm{N}) \# 407$ & (19) desempate $(\mathrm{N}) \# 54$ & \\
(20) desempenho $(\mathrm{N}) \#+403$ & & \\
(21) roubo $(\mathrm{N}) \# 380$ & & \\
(22) confronto $(\mathrm{N}) \# 353$ & & \\
\hline
\end{tabular}

Os produtos denotam tipicamente eventos, processos, situações, sendo o valor eventivo o mais representado. Existem, todavia, outros semantismos, que sumariamente se arrolam.

Para além de evento (abraço, arranque, ataque, combate, debate, degelo, embarque, espera, roubo, tosquia, voo), estes nomes denotam também objeto do evento (arranca 'pernada ou haste que se arrancou', caça) e ainda, em função do verbo de base, estado (amuo, desemprego, sufoco, zanga). Menos frequentemente denotam agente humano (bufo, pilho 'gatuno', de pilhar 'roubar'), objeto/instrumento não mecânico (abafo, adorno, agasalho, fisga, lixa, trincha), locativos (abrigo, arrumo(s), atalho).

Não raro, um nome deste tipo apresenta diferentes semantismos (passeio 'evento de passear; local onde se passeia'; visita 'evento de visitar; o que visita') sendo a sua leitura determinada em função do cotexto.

(18) Este passeio tem dois metros de largura. [leitura locativa]

(19) O passeio durou mais de 7 horas. [leitura eventiva]

(20) Andava no passeio e caiu. [leitura eventiva/locativa]

(21) A visita foi longa. [leitura eventiva]

(22) A visita foi-se logo embora. [leitura agentiva]

(23) A visita não foi demorada. [leitura eventiva 'o ato de visita não demorou muito'/leitura agentiva 'o visitante não se demorou muito']

\section{Percurso e estatuto deste Processo derivacional AO LONGO DA HISTÓRIA DA LÍNGUA}

Recua pelo menos a Darmesteter (1877) a ideia de que os nomes deverbais não sufixados são denominações da língua popular e são anteriores aos sufixados corradicais. Assim é em alguns casos, mas não é legítimo generalizar esta assunção para o conjunto de derivados em análise, como se observa em alguns dados abaixo exibidos.

Reportando-se ao francês, Darmesteter (1877) considera que um processo de formação de nomes elegante e simples como o de formação deste tipo de nomes cedeu terreno à pressão da relatinização erudita que ocorreu após o século XVI: "un procédé de dérivation qui avait donné à la langue tants de mots élégants, nets, courts et simples, se réduit devant les envahissements de la langue savante, et ne trouve 
pour dernier refuge que la langue du peuple ou la langue spéciale". (Darmesteter (1877[1972], p. 53-54).

Assim, Darmesteter (1877[1972], p. 53) considera que a formação de nomes deste tipo foi de alguma forma cerceada pela pressão da norma culta, uma vez que consultation, dénonciation, diffamation, prononciation fizeram recuar ou desaparecer consulte, dénonce, diffame, prononce. A realidade linguística do português diverge um pouco da que é descrita por este neogramático, pois alguns dos nomes já documentados na Idade Média não foram substituídos por outros sufixados, tendo perdurado até aos nossos dias.

O quadro seguinte permite observar que há nomes deverbais não sufixados abonados desde muito cedo na história da língua, e assim acontece com nomes marcados por valores de frequência muito díspares, que vão de ajuda(N) \#1233 a $\operatorname{paga}(\mathrm{N}) \# 24$.

Quadro 3 - Nomes deverbais não sufixados e suas frequências CORLEX

\begin{tabular}{|c|c|c|c|}
\hline \multirow{2}{*}{$\begin{array}{l}\text { Séculos } \\
\text { Séc. XIII }\end{array}$} & \multicolumn{3}{|c|}{ Nomes deverbais não sufixados e suas frequências CORLEX } \\
\hline & $\begin{array}{l}\operatorname{ajuda}(\mathrm{N}) \# 1233 \\
\operatorname{roubo}(\mathrm{N}) \# 380\end{array}$ & pertença $(\mathrm{N}) \# 95$ & $\operatorname{paga}(\mathrm{N}) \# 24$ \\
\hline Séc. XIV & ensino(N) \#1851 & $\begin{array}{l}\text { combate }(\mathrm{N}) \# 994 \\
{[\text { combato] }}\end{array}$ & $\operatorname{arroto}(\mathrm{N}) \# 15$ \\
\hline Séc. XV & $\begin{array}{l}\text { emprego(N) \#2200 } \\
\text { debate(N) \#1631 } \\
\text { queima(N) \#130 }\end{array}$ & $\begin{array}{l}\operatorname{urro}(\mathrm{N}) \# 27 \\
\operatorname{abafo}(\mathrm{N}) \# 16\end{array}$ & $\begin{array}{l}\operatorname{salga}(\mathrm{N}) \# 9 \\
\operatorname{varejo}(\mathrm{N}) \# 6\end{array}$ \\
\hline Séc. XVI & $\begin{array}{l}\text { toque }(\mathrm{N}) \# 457 \\
\text { desvio(N) \#505 } \\
\text { corte }(\mathrm{N}) \# 500 \\
\operatorname{amostra}(\mathrm{N}) \# 407\end{array}$ & $\begin{array}{l}\operatorname{arrepio}(\mathrm{N}) \# 139 \\
\text { abalo(N) \#96 } \\
\text { saque(N) \#65 }\end{array}$ & $\begin{array}{l}\operatorname{est}(\mathrm{r}) \operatorname{alo}(\mathrm{N}) \# 51 \\
\operatorname{trago}(\mathrm{N}) \# 37 \\
\operatorname{mexerico}(\mathrm{N}) \# 23\end{array}$ \\
\hline Séc. XVII & $\begin{array}{l}\operatorname{visita}(\mathrm{N}) \# 2269 \\
\operatorname{apoio}(\mathrm{N}) \# 3636\end{array}$ & $\begin{array}{l}\text { permuta }(\mathrm{N}) \# 76 \\
\text { retoque }(\mathrm{N}) \# 66\end{array}$ & $\begin{array}{l}\text { desgoverno(N) \#10 } \\
\text { enfado(N) \#7 }\end{array}$ \\
\hline Séc. XVIII & $\begin{array}{l}\operatorname{recuo}(\mathrm{N}) \# 169 \\
\operatorname{festejo}(\mathrm{N}) \# 109\end{array}$ & escape $(\mathrm{N}) \# 94$ & desempate $(\mathrm{N}) \# 54$ \\
\hline Séc. XIX & $\begin{array}{l}\text { destaque }(\mathrm{N}) \# 9531 \\
\text { espera }(\mathrm{N}) \# 2184 \\
\text { consumo(N) \#1575 } \\
\text { ataque }(\mathrm{N}) \# 1512 \\
\text { desemprego(N) \#942 } \\
\text { atraso(N) \#864 } \\
\operatorname{voo}(\mathrm{N}) \# 838 \\
\text { abandono(N) \#437 }\end{array}$ & $\begin{array}{l}\text { desempenho(N) \#403 } \\
\text { confronto(N) \#353 } \\
\text { anseio(N) \#122 } \\
\text { ajuste }(\mathrm{N}) \# 95 \\
\text { relance }(\mathrm{N}) \# 88 \\
\text { troça }(\mathrm{N}) \# 87 \\
\text { desembarque }(\mathrm{N}) \# 79 \\
\text { zanga }(\mathrm{N}) \# 77\end{array}$ & $\begin{array}{l}\text { rateio(N) \#65 } \\
\text { embarque }(\mathrm{N}) \# 58 \\
\text { uivo(N) \#51 } \\
\text { palpite(N) \#37 } \\
\text { apanha(N) \#36 } \\
\text { transbordo(N) \#21 } \\
\text { chilreio(N) \#9 } \\
\text { desempenho(N) \#6 }\end{array}$ \\
\hline Séc. XX & $\operatorname{anseio}(\mathrm{N}) \# 122$ & - & - \\
\hline
\end{tabular}

Como este quadro revela, alguns nomes deverbais não sufixados são contemporâneos dos cognatos sufixados (paga e pagamento, ambos abonados no séc. XIII; voo [XIX] e voadura [1844]), alguns são anteriores aos sufixados (amostra [1500] vs. amostragem [1899]; arroto [XIV] vs. (a)rotamento [XV]; governo [XIII] governança e 
governaçon [XV]); outros são posteriores a estes (confronto [1881] vs. confrontação (do fr. confrontation) [XVI]; espera [1813] vs. esperança [XIII]; voo [XIX] vs. avoamento [XVI].

Talvez pela proximidade cronológica e/ou formal em alguns casos os dicionários consideram o nome não sufixado como 'equivalente a' ou como 'variante de' um cognato sufixado: assim acontece com emperro (de emperrar), que Houaiss descreve como exemplo de derivação regressiva de emperrar e como "variação de emperramento".

$\mathrm{Na}$ amostra acima exposta regista-se grande volume de nomes deverbais não sufixados no séc. XIX, mas falta apurar se este estado de coisas não se deve à maior acessibilidade das fontes nas quais os dicionários etimológicos e as bases de dados se escudam. Uma análise de fontes mais recuadas no tempo ajuda a apurar com mais acuidade se a irrupção de nomes deste tipo avulta nestes séculos mais recentes, ou se remonta a épocas mais remotas.

Quando comparado com outros processos genolexicais, a formação de nomes deverbais não sufixados não se apresenta como das mais produtivas. Freitas (1990), com base no quadro teórico e metodológico de Dressler, demonstra que no cômputo dos processos de Formação de Palavras, também em português a subtração — e, segundo o mesmo autor, nela incluída a formação de nomes deverbais não sufixados encarada como "derivação regressiva" - ocupa o lugar mais modesto na escala de iconicidade construcional dressleriana. Face à afixação, à afixação + modificação, à modificação, à conversão, a subtração é encarada como o procedimento com o mais baixo grau de "naturalidade" ou de iconicidade, sendo por isso a sua produtividade das mais baixas nas línguas naturais (cf. quadro seguinte).

Quadro 4 - Dados numéricos da produtividade das Regras de Formação de Palavras (numeração árabe: n. ${ }^{\circ}$ de RFP), extraído de Freitas (1990, p. 86).

\begin{tabular}{c|c|c|c|c|c|c} 
Linguas & $\begin{array}{c}\text { Grau de } \\
\text { produtividade }\end{array}$ & Afixaçãao & $\begin{array}{c}\text { Afixação } \\
\text { modificação }\end{array}$ & Modificasãão & Conversão & Subtração \\
\hline \multirow{3}{*}{ Alemão } & Produtivo & 22 & 16 & 1 & 2 & $(1)$ \\
& Semiprodutivo & 57 & 8 & - & - & - \\
& Improdutivo & 2 & 3 & 3 & 1 & - \\
\hline \multirow{3}{*}{ Português } & Produtivo & 45 & 11 & - & 6 & 1 \\
& Semiprodutivo & 27 & 3 & - & 1 & - \\
& Improdutivo & 13 & 3 & - & - & - \\
\hline
\end{tabular}

O estudo mais completo sobre formação de nomes deverbais não sufixados, o de Rodrigues (2001), que conjuga para a análise dos mesmos dimensões morfológicas, semânticas, argumentais, diacrónicas, seja das bases, seja dos derivados, elenca 1323 nomes deste tipo, filtrados à luz do entrecruzamento das dimensões mencionadas.

Face a estes dados numéricos, é abissal a comparação com a enorme representação de nomes sufixados cujas bases sejam verbos portadores de -iz- ou de outro sufixo assaz produtivo, pelo que se corrobora que os nomes deverbais não sufixados estão muito menos representados na língua que os sufixados, e têm um potencial de produtividade muito menor. 
Em todo o caso, há registo de formações novas que não se encontram ainda dicionarizadas e contidas nas bases disponíveis.

Não obstante, existe a possibilidade de se construírem novos nomes deverbais não sufixados, estando ativa não apenas por escritores, sempre muito criativos, mas também pelos falantes comuns, mormente na linguagem mais expressiva e em registos marcados por maior subjetividade.

Da base de dados coligida por Rodrigues (2001) e no Houaiss não constam estes nomes certamente formados e/ou difundidos a posteriori:

(24) (um) amasso 'ato ou efeito de amassar. [informal] Troca de contactos íntimos' registado no Aurélio (https://dicionariodoaurelio.com/amasso) e no Dicionário Priberam da Língua Portuguesa [em linha], 2008-2013, https://www.priberam.pt/dlpo/amasso [consultado 15 dez. 2017].

(25) (uma) curte '[informal] Coisa, facto ou pessoa que provoca prazer. = curtição' (Dicionário Priberam da Língua Portuguesa [em linha], 2008-2013, https://www.priberam.pt/dlpo/curte [consultado 13 dez. 2017].

(26) (a) funda (de fundir) quantidade que determinada porção de matéria-prima funde, no processo da sua transformação: 'quantidade de litros de azeite por cada $100 \mathrm{~kg}$ de azeitona’ (http://infinitoemais.blogspot.pt/2013/12/epoca-doazeite-visita-um-lagar.html); 'Ato de produzir bem ou produzir muito (falandose de uvas, azeitonas, searas' (cf. https://dicionariodoaurelio.com/funda).

São criações expressivas de Guimarães Rosa e de Mário Palmério e registadas por Martins (2008), mas não dicionarizadas:

(27) o agito (agitar)

(28) o atrapalho (atrapalhar)

(29) o chego (chegar)

(30) o desconfio (desconfiar)

(31) o oscilo (oscilar)

(32) o vibro (vibrar)

Como estes exemplos de criação literária mostram, são porosas as fronteiras entre alguns nomes deverbais não sufixados e os formados por truncação. Gonçalves (2016, p. 62) interpreta agito 'acontecimento festivo' como uma extensão semântica de 'estado ou circunstância que envolve excesso de agitação', mas nada invalida que se trate de um deverbal não sufixado. De igual modo, considerar fico e chego como particípios irregulares de chegar e ficar carece de demonstração. Não obstante, nestes casos nada impede que eles sejam encarados como construídos deverbalmente, sem recurso a sufixação, e não como formas truncadas dos homólogos sufixados. De resto, a alteração de género entre os sufixados e os não sufixados não é a mais típica da truncação (cf. o boteco, o botequim, a belê, a beleza, a madruga, a madrugada, o salafra, o salafrário), pelo que outra abordagem que não a de se tratar de nomes deverbais não sufixados exige uma fundamentação mais sólida.

A formação de nomes deste tipo é comum a outras línguas românicas, e tem não raro um forte valor de expressividade, como o assinala Kortas (2003, p. 163) para o francês: cambrioler $>$ cambriole, diner $>$ dine, doper $>$ dope, dormir $>$ dorme, remballer> remballe 'ação fraudulenta de reembalamento de produtos frescos para lhes prorrogar a data de validade'. 
Nas crianças, a aquisição deste tipo de estruturas ocorre em fases algo tardias da produção derivacional; os exemplos por nós recolhidos não são marcados sob o ponto de vista da expressividade.

(33) Uma abra: O muro tem aqui uma abra (abertura) (29-2-2004: 7 anos, 11 meses).

(34) Um arranco: Aquele carro faz um arranco pior que o teu (3-3-2003: 6 anos, 11 meses) 'ato ou efeito de arrancar; movimento impetuoso e inesperado'.

(35) Um ladro: A cadela deu um ladro .... que o meu coração pulou! (1-3-2003: 6 anos, 11 meses).

\section{CONCLUSÕES}

Desde muito cedo e até aos nossos dias a Língua Portuguesa dispõe de um processo de formação de nomes deverbais não sufixados (afronta, ajuste, despiste, desvio, embarque, engorda, esforco, gargarejo, murmurejo, passeio, voo) cujo estatuto desafia as teorias linguísticas e os modelos morfológicos. Além de a sua formação estar sujeita a constrições muito fortes (Rodrigues, 2009, 2016), a sua representatividade na língua não ombreia com a formação de nomes por afixação, e a sua baixa produtividade pode justamente dever-se à concorrência com outros processos de nominalização, nomeadamente os sufixais (em -ção, -mento, -agem).

Não obstante, a sua presença faz-se sentir não apenas em áreas de especialização muito delimitadas, como as do mundo agro-alimentar e das atividades de cunho mais artesanal e sustentável, como em zonas de enorme relevância para a vida moderna, como as que denotam situações laborais (emprego, desemprego), atividades e estados de natureza vária, mas fulcrais no mundo hodierno (abandono, ajuda, ataque, apoio, atraso, combate, confronto, consumo, debate, ensino, espera, roubo, visita, voo), para mencionar alguns dos mais ilustrativos e representados.

O estudo efetuado revela que há nomes deverbais não sufixados abonados desde muito cedo na história da língua, e que pervivem até aos nossos dias (cf. ajuda, paga).

Alguns nomes deverbais não sufixados são contemporâneos dos cognatos sufixados (paga e pagamento), alguns (amostra, governo) são anteriores aos sufixados (amostragem, governança e governaçon), outros são posteriores (confronto, espera) aos sufixados (confrontação, esperança), pelo que a cronologia relativa da produção de uns e de outros não permite extrair ilações fortes sobre os fluxos de interação entre os dois padrões de formação de nomes deverbais - o que envolve sufixação, claramente mais representado, e o que não envolve sufixos, menos representado e certamente menos disponível na língua.

$\mathrm{Na}$ amostra analisada regista-se grande volume de nomes deverbais não sufixados no séc. XIX, mas falta apurar se este estado de coisas não se deve à maior acessibilidade das fontes nas quais os dicionários etimológicos e as bases de dados se escudam. 


\section{REFERÊNCIAS}

Azeredo JC de. Gramática Houaiss da Língua Portuguesa. Rio de Janeiro: Publifolha; 2013.

Basílio M. Formação e classes de palavras no português do Brasil. São Paulo: Contexto; 2004.

Bechara E. Moderna Gramática Portuguesa. 37ª edição, revista, ampliada. Rio de Janeiro: Nova Fronteira; 2009.

CORLEX Léxico Multifuncional Computorizado do Português Contemporâneo. [citado 9 jan. 2018]. Disponível em: http://www.clul.ul.pt/pt/recursos/88-project-multifunctional-computational-lexiconof-contemporary-portuguese.

Cunha AG da. Dicionário Etimológico Nova Fronteira da Língua Portuguesa. $2^{\mathrm{a}}$ ed. Rio de Janeiro: Editora Nova Fronteira; 1986.

Darmesteter A. De la création de mots nouveaux dans la langue française et des lois qui la régissent (Réimpression de l'édition de Paris, 1877). Genève: Slatkine Reprints; 1972.

Davies M, Ferreira M. Corpus do Português. [citado 9 jan. 2018]. Disponível em: http://www.corpusdoportugues.org.

Dicionário Aurélio da Língua Portuguesa. [citado 19 dez. 2017]. Disponível em: https://dicionariodoaurelio.com.

Dicionário Priberam da Língua Portuguesa [em linha], 2008-2013. [citado 19 dez. 2017]. Disponível em: https://www.priberam.pt/dlpo.

Diez F. Grammaire des langues romanes. $3^{\text {a }}$ ed. Paris: A. Franck; 1874.

Freitas MS. A derivação regressiva na perspectiva do modelo Dressler. Algumas considerações. [dissertação]. Universidade Federal do Paraná. Curitiba; 1990.

Gamarski L. A derivação regressiva: um estudo da produtividade lexical em português. Goiânia: CEGRAF; 1988.

Gonçalves CA. Atuais tendências em formação de palavras. São Paulo: Contexto; 2016.

Kehdi V. A derivação regressiva em português. Filologia e Lingüística Portuguesa. 1998;2:205-213.

Kortas J. Expressivité dérivationnelle en français contemporain: noms d'action. Studia Romanica Posnaniensia. 2003;29:155-170.

Lobato L. A derivação regressiva em português: conceituação e tratamento gerativo. In: Miscelânea de estudos linguísticos, filológicos e literários in memoriam Celso Cunha. Rio de Janeiro: Nova Fronteira; 1995. p. 205-30.

Martins NSA. Introdução à Estilística: a expressividade na língua portuguesa. $4^{a}$ ed. revista. São Paulo: EDUSP; 2008.

Nunes JJ. Compêndio de gramática histórica portuguesa. 9ª ed. Lisboa: Clássica Editora; 1989[1919].

Resende M. Derivação regressiva e construções com verbos leves: um estudo sobre aspecto lexical. [dissertação]. Curitiba: Universidade Federal do Paraná; 2016.

Rey A. Dictionnaire historique de la langue française. Paris: Nathan; 2011. 
Rio-Torto G, editora. Gramática derivacional do português. Coimbra: Coimbra University Press; 2016.

Rio-Torto G. Desafios em morfologia: história e (re)conhecimento. In: Viaro M, editor. Morfologia histórica. São Paulo: Cortez; 2013. p. 31-57.

Rodrigues A. A construção de postverbais em português. Porto: Granito Editores; 2001.

Rodrigues A. Aspectos da formação dos substantivos postverbais do português. Filologia e Linguística Portuguesa. 2004;6:7-37.

Rodrigues A. Portuguese converted deverbal nouns: constraints on their bases. Word Structure. 2009;1:69-107.

Rodrigues A. Deverbais que resultam da conversão do radical. In: Rio-Torto G, et al. Gramática derivacional do português. Coimbra: Coimbra University Press; 2016. p. 235-238. 